\title{
Uma vida entre insetos e livros: entrevista com Nelson Papavero
}

\author{
A life among insects and books: \\ an interview with Nelson Papavero
}

Entrevista com Nelson Papavero

\section{Concedida a \\ Bruna Klassa}

Pós-graduanda em Ensino, História e Filosofia da Ciência e Matemática/ Universidade Federal do ABC. bklassa@gmail.com

\section{Charles Morphy D. Santos}

Professor adjunto do Centro de Ciências Naturais e Humanas/ Universidade Federal do $A B C$ charlesmorphy@gmail.com
KLASSA,Bruna; SANTOS, Morphy D., Charles. Uma vida entre insetos e livros: entrevista com Nelson Papavero. História, Ciências, Saúde Manguinhos, Rio de Janeiro, v. 19, n.4, out.-dez. 2012, p.1319-1331.

\section{Resumo}

Nelson Papavero é um dos principais expoentes da zoologia brasileira. Sua contribuição para a ciência a partir da segunda metade do século XX é decisiva, com publicações nas áreas de zoologia, sistemática, biogeografia e história da ciência, atuação em cursos de pós-graduação e na formação de professores e alunos. Foi o principal introdutor e disseminador da sistemática filogenética hennigiana no Brasil. Sua participação ativa na criação dos Cursos Especiais de Sistemática Zoológica do Conselho Nacional de Desenvolvimento Científico e Tecnológico e os inúmeros cargos administrativos que acumulou durante sua trajetória acadêmica foram fundamentais para o desenvolvimento da zoologia e da biologia comparada no Brasil. Sua atuação alcançou ainda outros países da América Latina, como México e Argentina.

Palavras-chave: Nelson Papavero (1942-); história da ciência; Willi Hennig (1913-1976); sistemática filogenética; zoologia.

\section{Abstract}

Nelson Papavero is one of the top representatives of Brazilian zoology. His decisive contributions to this science began in the second half of the twentieth century, when he started publishing in the areas of zoology, systematics, biogeography, and the history of science while also working at graduate courses and training teachers and students. He was key to the introduction of Hennig's phylogenetic systematics in Brazil and its chief advocate. His active participation in the creation of the Special Courses on Zoological Systematics within the National Council for Scientific and Technological Development and his work at numerous administrative posts which he held during his academic career were vital to the development of zoology and comparative biology in Brazil. His endeavors also reached into other Latin American countries, like Mexico and Argentina.

Keywords: Nelson Papavero (1942-); history of science; Willi Hennig (19131976); phylogenetic systematics; zoology. 
A história da sistemática é marcada por numerosas escolas de pensamento que buscaram não só organizar a diversidade biológica segundo regras de nomenclatura, mas também deixar transparecerem suas afinidades evolutivas a fim de estabelecer grupos naturais. Dos muitos sistematas que lançaram propostas classificatórias na primeira metade do século $\mathrm{XX}$, poucos conseguiram introduzir mudanças conceituais necessárias para o desenvolvimento desse campo das ciências biológicas. Em Phylogenetic systematics, obra traduzida e ampliada a partir da edição alemã lançada em 1950, o entomólogo alemão Willi Hennig (1966) propôs um sistema de classificação baseado no agrupamento de organismos que tornou possível o reconhecimento das afinidades evolutivas entre eles.

Para a sistemática filogenética, um dos pilares do evolucionismo moderno, as relações de parentesco entre as espécies só podem ser obtidas a partir da análise de atributos homólogos, que são características no geral morfologicamente semelhantes surgidas no ancestral comum dos grupos considerados no estudo e que se modificam com o passar das gerações. Os membros anteriores de um cavalo, nossos braços e as asas de uma ave constituem um exemplo clássico de estruturas homólogas. Diferentemente da sistemática praticada desde a teoria sintética da evolução, o método proposto por Hennig sugere que apenas as relações de grupos/irmãos poderiam ser reconhecidas, e não as de ancestral descendentes. Uma árvore filogenética, também chamada de cladograma, é o resultado da análise das homologias. É utilizada para determinar se um grupo taxonômico está mais próximo de outro em relação a um terceiro, e nunca se ele é o ancestral direto de outro a ele adjacente. Assim, não há nenhuma maneira de se estabelecerem os verdadeiros ancestrais para qualquer grupo recente, o que faz com que as espécies fósseis sejam tratadas da mesma maneira que os demais táxons terminais.

No método hennigiano, o conceito de grupo monofilético é fundamental: como evolução significa descendência com modificação no tempo a partir de um ancestral comum; o grupo monofilético ou natural é definido como aquele que inclui o ancestral comum e todos os seus descendentes, que compartilham homologias resultantes do processo evolutivo. É esse tipo de agrupamento o único que reflete a realidade da evolução e, portanto, aproxima a prática sistemática das ideias evolutivas de Charles Darwin e Alfred Wallace. Para Santos (2008), a popularização do pensamento filogenético hennigiano nos anos 1970 foi de encontro à ortodoxia da sistemática da época e levou ao questionamento dos fundamentos da prática classificatória na biologia comparada. No Brasil, o introdutor e um dos grandes responsáveis pela disseminação da sistemática filogenética foi o zoólogo dipterista, sistemata, biogeógrafo e historiador da biologia professor Nelson Papavero.

Paulistano, nascido em março de 1942, Papavero liderou a divulgação e o aperfeiçoamento das discussões evolutivas no ambiente acadêmico brasileiro na segunda metade do século XX, incentivando a introdução de conceitos teóricos de sistemática filogenética nas pesquisas e uma visão mais histórica e filosófica dos fatos estudados. Essa postura tornou mais robustos os estudos sobre a diversidade, especialmente na zoologia. Os animais deixaram de ser analisados apenas no nível de espécie ou gênero e passaram a ser tratados como populações inseridas em um processo evolutivo de descendência com modificação a partir de ancestrais comuns, a base do pensamento filogenético. 
Entre 1961 e 1967, Papavero estagiou no Departamento de Zoologia da Secretaria da Agricultura do Estado de São Paulo durante sua graduação em ciências biológicas pela Universidade de São Paulo. Doutorou-se em 1971, tendo como orientador o professor Paulo Emílio Vanzolini, eminente zoólogo brasileiro e defensor da teoria biogeográfica dos refúgios, à luz da qual procurou explicar a diversificação biológica na Amazônia a partir de ciclos de diminuição e aumento de temperatura que teriam ocorrido durante o final do Pleistoceno (período geológico compreendido entre 2.588 .000 e 11.700 anos atrás).

Papavero foi um dos principais colaboradores do Programa Nacional de Zoologia do Conselho Nacional de Desenvolvimento Científico e Tecnológico (PNZ-CNPq), procedendo em 1980-1981 a um levantamento da situação dessa ciência no Brasil. Como pioneiro na divulgação da sistemática filogenética hennigiana, reacendeu as discussões teóricoevolucionistas introduzidas por Vanzolini nas décadas de 1960 e 1970. Além disso, Papavero foi encarregado da área científica do Museu Paraense Emílio Goeldi, na condição de vice-diretor (1986). Por três mandatos consecutivos (1982-1988), foi presidente da Sociedade Brasileira de Zoologia (SBZ). Sua gestão marcou a história desse órgão, pois nela teve início a publicação da Revista Brasileira de Zoologia e da série de manuais e técnicas para preparação de coleções zoológicas (Zarur, 1994). Somam-se a isso a implantação de minicursos acadêmicos voltados para a pesquisa em zoologia (de tópicos que raramente faziam parte dos currículos das áreas biológicas); a promoção dos Cursos Especiais de Sistemática Zoológica (responsáveis pela orientação de vários pesquisadores para o estudo e aplicação das modernas teorias de sistemática); e a criação do Centro de Identificação de Insetos Fitófagos (Universidade do Paraná) e do Centro de Identificação de Insetos Urbanos (Fundação Zoobotânica do Rio Grande do Sul). Em 1989, Papavero recebeu diploma de Honra ao Mérito da SBZ e em 1994 foi homologado seu sócio honorário. Mais recentemente, em 2009, foi nomeado doutor honoris causa pela Universidade Federal Rural do Rio de Janeiro (UFRRJ). Em junho de 2011, a Universidade Nacional de Tucumán propôs sua designação como professor honorário da instituição.

A obra de Papavero engloba, além de pesquisas em sistemática, outros campos da biologia comparada, como a biogeografia (Papavero, Teixeira, Llorente-Bousquets, 1997; Papavero, Teixeira, 2001). Conforme se destaca no livro Introdução histórica à biologia comparada com especial referência à biogeografia (Papavero, Balsa, 1986, p.9): "na segunda metade do século $\mathrm{XX}$, a sistemática e a biogeografia se transformam pela primeira vez em Ciências, com um grande poder de teste e previsão, livrando-se definitivamente das peias do passado e do ranço aristotélico". A abordagem introduzida por Papavero e Balsa rompeu com o estilo de pesquisa existente na zoologia brasileira até então, caracterizado por um viés puramente descritivo e não analítico.

Ao longo de sua carreira, Papavero tem demonstrado profunda preocupação com as condições de ensino e de pesquisa de biologia, tendo sido diretamente responsável pela formação de um grande grupo de biólogos e professores universitários que hoje atuam e orientam projetos fundamentados na sistemática filogenética hennigiana e em seus desdobramentos. Aposentado pelo Museu de Zoologia da Universidade de São Paulo (USP) em 1997, até recentemente ainda ministrava cursos de pós-graduação em centros universitários brasileiros e estrangeiros, além de participar ativamente de projetos de 
pesquisa, como o Biota-Fapesp, responsável pelo inventário da diversidade biológica do estado de São Paulo. A entrevista a seguir foi realizada em 13 de dezembro de 2011, no Museu de Zoologia, em São Paulo.

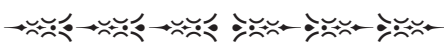

Quando e onde o senhor nasceu e cresceu?

Nasci em 9 de março de 1942, em São Paulo. Meu pai trabalhava numa fábrica de produção de encanamento, e minha mãe era dona de casa. Estudei no colégio Nossa Senhora do Carmo, no Centro da cidade de São Paulo, na rua do Carmo, atrás do Ministério da Fazenda.

\section{Como foi sua trajetória durante a graduação?}

Depois que terminei o colegial, fiz seis meses de cursinho. Depois desisti do cursinho e prestei vestibular para história natural na Universidade de São Paulo (USP). No fim do meu primeiro ano, em 1961, é que mudaram o nome para ciências biológicas. Fiz o curso no período noturno. De dia trabalhava no museu ${ }^{1}$ e à noite não dava para cursar muitas disciplinas. Houve um ano em que fiquei muito desgostoso do curso e não tinha nenhuma matéria preferida. Só o estágio me interessava de fato. Aqui no museu eu fazia o que realmente gostava, lá na universidade parecia perda de tempo.

Mas alguns professores foram importantes e marcaram meus anos de graduação. Um deles foi o professor Cláudio Froehlich, que hoje está na Faculdade de Filosofia, Ciências e Letras de Ribeirão Preto, da USP. Ficamos amigos logo cedo. Ele tem um conhecimento de zoologia inacreditável. Também tinha um professor de paleontologia, Antônio Rocha Campos. Foi o único que trouxe algo original, porque na época ele tinha vindo dos EUA, falava de deriva continental ${ }^{2}$, e outras coisas que me interessavam.

Logo que entrei na faculdade, um colega veio com a notícia de que no Departamento de Zoologia tinham aberto vagas para estagiário. Carvalho Pinto ${ }^{3}$ criou algumas centenas de vagas para estagiários no estado. Era meu sonho vir para cá. No primeiro dia que pude, vim me apresentar e entrei como estagiário. Comecei como estagiário com o doutor Messias Carrera ${ }^{4}$, já com insetos dípteros. Quando havia tempo, saíamos em excursão. Eu estava aprendendo mesmo. Quando o Messias se aposentou, e fiquei livre, fazia o que eu queria. Então comecei a aumentar a coleção, fazer coleta e estudar a bibliografia. O estágio durou até eu me formar, em 1967. Depois houve vários concursos e nomeações no MZUSP.

\footnotetext{
${ }_{1}^{1}$ Papavero refere-se ao Museu de Zoologia da USP, o MZUSP, que, à época, era o Departamento de Zoologia da Secretaria de Agricultura, Indústria e Comércio do Estado de São Paulo.

${ }^{2}$ De acordo com a ideia de deriva continental, os continentes, formados por placas tectônicas, estão em contínuo processo de afastamento, uns em relação aos outros.

${ }^{3}$ Carlos Alberto de Carvalho Pinto foi governador do estado de São Paulo entre 1959 e 1963.

${ }^{4}$ Messias Carrera (1907-1994) foi biologista-chefe da Seção de Insetos do que viria a ser o MZUSP.
} 
Aí virei biologista. Nunca fiz estágio em nenhuma outra área, apenas aqui no museu. Sempre gostei do MZUSP. Entrei aqui quando ainda era o Departamento de Zoologia da Secretaria de Agricultura, Indústria e Comércio do Estado de São Paulo. Só passamos para a USP em 1969. Fiz concurso aqui ainda no departamento, e quando a USP o incorporou, passei a ser professor de lá, mas sempre trabalhando no museu.

\section{Em que momento o senhor resolveu se dedicar também à teoria sistemática?}

Comecei já na minha tese de doutoramento, porque o Paulo Vanzolini tinha lançado a teoria dos refúgios e todos os orientandos dele na época a aplicavam. Também trabalhei com refúgios e vi que a ideia estava incorreta. Depois, enquanto estudava dípteros, entrei em contato com o trabalho de Willi Hennig, que era dipterista, vi que aquilo era um negócio revolucionário. Foi por onde começamos a estudar teoria, Nelson Bernardi ${ }^{5}$ e eu. Mas só fui começar a publicar em sistemática muito mais tarde. Comecei com dípteros, sobre os quais publiquei os meus três primeiros trabalhos (Carrera, Papavero, 1962; Machado-Alisson, Papavero, 1962; Papavero, 1962). Artigos com teoria só apareceram depois. Naquela época, gostava de preparar descrições e fazer manuais.

\section{Conte sobre a sua relação com os professores Nelson Bernardi e Ângelo Pires do Prado.}

Conheço o Ângelo desde que ele era estudante no Instituto Oswaldo Cruz, no Rio de Janeiro. Depois da instauração do regime militar, ele veio para São Paulo, para Campinas. O Ângelo foi o primeiro que entendeu direitinho a sistemática filogenética e o primeiro que fez um trabalho hennigiano de fato. Talvez tenha sido o primeiro em toda a América Latina, em 1969, quando descreveu a família Syringogastridae, de insetos dípteros. O primeiro grande trabalho sobre dípteros (feito por outro autor que não Hennig) usando a sistemática filogenética foi do sueco Lars Brundin ${ }^{6}$, em 1966, e o Ângelo publicou sua pesquisa três anos depois (Prado, 1969), o que é incrível. Talvez seja o primeiro na América. Já o Bernardi conheci na faculdade. Nós dois estávamos lendo o mesmo livro de linguística, e foi amizade logo de cara. Eu o trouxe para o museu. Ele sempre foi teórico, superteórico! De vez em quando publicava um trabalho curto de taxonomia, mas nunca publicou muito em revista, a não ser um artigo propondo o conceito de merofilético ${ }^{7}$ em 1981. Foi ele quem deu o primeiro curso de sistemática filogenética aqui no museu.

Considero o Ângelo o primeiro sistemata hennigiano do Brasil. Depois pouco a pouco foram saindo os primeiros trabalhinhos de outros autores, bem mais tarde, nos anos 1980. Nesse momento começou a influência americana com a cladística numérica, que é outro problema, por erros de lógica, de polarização de caracteres com mais de dois estados e outros...

\footnotetext{
${ }^{5}$ Nelson Bernadi é professor aposentado da Universidade Estadual Paulista Júlio de Mesquista (Unesp), de Botucatu.

${ }^{6}$ Lars Brundin (1907-1993) foi um entomólogo sueco que utilizou métodos filogenéticos para demonstrar a concordância entre distribuições de dípteros e a movimentação das placas tectônicas.

${ }^{7}$ Merofiléticos são os grupos não naturais, isto é, não monofiléticos.
} 
O senhor leu o trabalho original do Hennig? A versão em alemão ou em inglês?

Li o Phylogenetic systematics de 1966 em inglês; o alemão, de 1950, era impossível. O primeiro trabalho do Hennig que me chamou atenção foi o "Flügelgeäder und System der Dipteren unter Berücksichtigung der aus dem Mesozoikum beschriebenen Fossilien", que ele publicou no volume quatro do Beiträge zur Entomologie (Hennig, 1954), se não me engano, em que ele faz a homologia da venação da asa dos Diptera. Um trabalho maravilhoso, revolucionário, que mudou para melhor a classificação das famílias de dípteros e a posição dentro deles de certos gêneros antes considerados enigmáticos. Todos os trabalhos dele foram revolucionários. Mas o alemão dele é impossível. Quando saiu em 1965 o resumo do livro de 1950, no Annual Review of Entomology (Hennig, 1965), e então a publicação em 1966, começamos a estudar, mas demorou um tempo porque sou muito lento...

\section{Como foi o seu doutorado?}

Escolhi um grupo de dípteros asilídeos para fazer uma revisão, que era um grupo gondwânico. ${ }^{8}$ Em 1971 e 1972, estive na Europa para ver os holótipos ${ }^{9}$, e acabei publicando o trabalho.

Durante o doutorado, que foi de 1969 a 1971, ganhei uma bolsa Guggenheim em 1970. Como ainda não tinha terminado o doutorado, devo isso ao Vanzolini; sem ele eu não teria conseguido. Em 1971 eu me doutorei, casei-me com Claude ${ }^{10}$, e fomos para a Europa. Antes ficamos três meses no EUA e depois, oito na Europa. Visitamos os museus todos.

Não fiz mestrado porque, na época, não era necessário. O bom do sistema do estágio é que em poucos anos era possível tornar-se especialista. No MZUSP, comecei a comprar as coleções dos coletores profissionais e as coleções privadas. Consegui aumentar tudo aqui, a coleção e a bibliografia. Em 1965 comecei o catálogo dos Diptera. Então eu tinha trabalho à vontade! Nunca quis trabalhar com outro grupo que não esse.

O senhor mantinha correspondência com Hennig? Como entrou em contato com ele e como se conheceram?

Sim, nos correspondíamos. Quando comecei o catálogo de Diptera, era costume mandálo para praticamente todos os dipteristas do mundo, em troca de separatas. O Hennig, quando nos correspondíamos, sempre mandava os trabalhos. Sempre foi muito generoso nisso. Quando estive na Alemanha em 1972, fui para a cidade de Ludwigsburg, ver os holótipos que o Erwin Lindner ${ }^{11}$ tinha coletado aqui no Chaco. Fiquei só uma semana em Ludwigsburg. Depois estive em Frankfurt. Na Alemanha, aproveitei, é claro, para falar com Hennig. Ele era uma pessoa extremamente simples. Muito agradável e muito simples.

\footnotetext{
${ }^{8}$ Um grupo gondwânico está distribuído na África e na América do Sul.

${ }^{9}$ Holótipo é o espécime físico que o autor do táxon designou no momento da sua descrição como sendo o material no qual a descrição foi baseada.

${ }^{10}$ Claude Guy Papavero, bacharel em ciências sociais e doutora em antropologia.

${ }^{11}$ Erwin Lindner (1888-1988), entomólogo alemão.
} 
Como foi sua recepção nessa viagem para a Alemanha?

Quem me recebeu oficialmente foi o professor Lindner. Ele tinha 83 anos na época e morreu com 100. Era um gigante! Sempre chegava cedo ao instituto. O Hennig morava na cidade e chegava mais tarde, mas sempre me lembro de que ele entrava, metia a cara na sala do Lindner e falava: "Guten Morgen, Herr Professor Doktor". E o Lindner respondia: "Guten Morgen, Herr Professor Doktor Doktor", porque o Hennig tinha também o título de doutor honoris causa... Ali também trabalhava Dieter Schlee, que foi uma figura muito interessante e pouco estimada na história da sistemática filogenética. Ele também era um gênio, chegou independentemente a muitas das ideias do Hennig, só que o Schlee infelizmente não falava inglês. Num sábado o Hennig me convidou para ir até a casa dele, ficamos batendo papo o dia inteiro até a noite. Ele era modesto, agradável, tinha uma memória incrível. Perguntou-me de todo mundo no Canadá, EUA, Brasil, dos trabalhos publicados por aqui... Sempre interessadíssimo em tudo. Discutimos várias questões sobre Diptera, entre elas a do gênero Heterostomus, que ele nunca tinha visto e que até hoje traz problemas para a classificação. O Hennig era muito simpático. Foi nessa época que comprei o livro dele em Frankfurt, o Insect phylogeny, que tinha saído em inglês (Hennig, 1981).

Em 1979 e 1980, o senhor foi para o CNPq. Como ocorreu a sua entrada no comitê de bolsas dessa agência?

O professor José Cândido, do Museu Nacional da Universidade Federal do Rio de Janeiro, que tinha um enorme poder no CNPq, nomeou-me, junto com o Arnaldo Coelho, também do Museu Nacional, para o comitê de zoologia. Ficamos dois anos nesse comitê, de 1979 a 1980. Depois, quando houve o segundo Plano Básico de Desenvolvimento Científico e Tecnológico (PBDCT) lá em Teresópolis (1979), houve uma reunião de zoólogos, conclamada pelo governo Geisel, e nós propusemos a criação da SBZ e do PNZ. Aí a coisa andou.

Tivemos uma reunião em Brasília, em 1980, na cobertura da sede central do CNPq, com uma discussão absolutamente inútil em que ninguém resolvia nada. De madrugada, no hotel, escrevi o plano, e no dia seguinte pedi à secretária do CNPq para datilografar e xerocar. Coloquei na mesa de todo mundo antes da reunião. Todos leram, gostaram e ele foi aprovado.

Escrevi tudo de madrugada, com cuidado para não acordar o Arnaldo que estava hospedado no mesmo quarto. Isso foi no Hotel das Américas. Convidamos o professor Reimar Schaden, que já estava na Universidade de Brasília, para passar para o CNPq e ficar com parte do programa. Tive que ir para lá, mas fiquei só um ano porque o CNPq era burocracia pura, não tinha muito que fazer lá. Eu estava em São Paulo e tudo estava aqui. Aí saíram os cursos e o programa de publicações, que não durou muito.

O que se pode falar de uma comparação entre o CNPq dos anos 1980 e o de hoje?

O CNPq foi mudando gradualmente. Muita coisa mudou. O que aconteceu de bom na época foi sair da cidade do Rio de Janeiro. O Rio de Janeiro dominava, era uma coisinha pequena, em família, patriarcal, e raramente sobravam bolsas de estudo para o resto do 
Brasil. Com a passagem para Brasília, quando o presidente do CNPq era José Dion de Melo Teles (1975-1979), natural do Piauí, o Conselho tornou-se realmente nacional, ampliado. Foi melhorando pouco a pouco até a situação atual.

Em 1982 foi criada a Revista Brasileira de Zoologia. Como isso ocorreu?

Era preciso ter uma revista nossa, da Sociedade Brasileira de Zoologia. O professor Tomé12 tinha deixado uma boa verba, e a sociedade estava em muito boa situação depois da gestão dele. Então, começamos a publicar. E publicava-se de tudo... Como era sociedade, aceitava-se qualquer contribuição.

\section{Como foi sua gestão na SBZ? Como o senhor a avalia?}

Eu gostei na época. Fui presidente da sociedade por seis anos (de 1982 a 1988). O que dava trabalho era a organização do Congresso Brasileiro de Zoologia, mas valia a pena. Uma das inovações foi a criação dos minicursos. Fui eu quem inventei, e todo mundo copiou. O primeiro minicurso foi dado em Belo Horizonte. Depois foi aumentando, aumentando e hoje é exponencial, tem em quilos. Mostrar para a criançada as áreas que eles não tinham acesso era muito interessante: folclore e etnobiologia (em Belém, trouxe os índios caiapós como professores), modelagem matemática, filosofia, etologia com o César Ades (que mudou a vida de muita gente, foi uma invasão de biólogo na psicologia). ${ }^{13}$ O César era esplêndido. Muita gente mudou para a psicologia. Os minicursos abriram o leque de muita gente.

\section{O que o levou ao Museu Paraense Emílio Goeldi? O senhor passou quanto tempo lá?}

Quando ainda estava no CNPq, como técnico do desenvolvimento científico para o PNZ, conheci o vice-presidente do CNPq, Guilherme de La Pena, e os zoólogos do Museu Goeldi pediram que eu concorresse à diretoria. Eu não tinha o menor interesse, mas de tanto insistirem (fizeram uma vaquinha para pagar minha passagem!), tive que fazer todo aquele processo de falar com pessoal, 'fazer campanha', coisa que odeio. Não tinha interesse, não sou administrador. E aí o Guilherme, que ganhou a diretoria do Museu Goeldi, me convidou para ser vice-diretor. Fiquei lá em 1986. Pedi afastamento da USP, sem ônus para a universidade. Saí do Goeldi no fim de 1986 porque não era possível fazer muita coisa com o pessoal disponível lá na época, havia pouco trabalho. Fiz o que dava para fazer, que foi arrumar as revistas e criar a pós-graduação em zoologia, que hoje está ótima.

Ao longo da sua carreira o senhor viajou profissionalmente ao México algumas vezes. Quais eram os objetivos dessas viagens?

\footnotetext{
${ }^{12}$ José Willibaldo Tomé, da Pontifícia Universidade Católica do Rio Grande do Sul, foi presidente da SBZ entre 1980 e 1982.

${ }^{13}$ César Ades (1943-2012) foi professor titular do Instituto de Psicologia e diretor do Instituto de Estudos Avançados da USP.
} 
Um dos alunos do Vanzolini, o Gerardo Lamas, trabalhou comigo durante o mestrado dele e um pouco no seu doutorado. Fez o mestrado sobre Diptera e o doutorado sobre Lepidoptera. Como ele era lepidopterista, mantinha correspondência com o Jorge LlorenteBousquets. ${ }^{14} \mathrm{O}$ Gerardo falou ao Jorge sobre o Museu de Zoologia. O Vanzolini tinha dado impulso na sistemática, e o próprio Jorge tinha sabido do nosso curso especial de sistemática zoológica, mas não havia conseguido bolsa para vir. No curso, o CNPq tinha convênio com os vários conselhos da América Latina, exceto com o Peru. Então avisamos aos alunos sobre todos os conselhos conveniados com o curso - os conselhos pagariam as passagens, e o CNPq pagaria as diárias. No fim, os conselhos não pagaram nada, mas o CNPq pagou as diárias sagradamente. Mas o Jorge não conseguiu vir, e o México é mais longe... Então ele resolveu me convidar para ir até lá em 1992. Foi amizade como a de irmãos. Começamos a trabalhar juntos; ele também tem interesses teóricos, e criamos os cursos no México. As publicações também foram imensas, devido à facilidade de publicação por lá. Fora que o México é o país mais lindo do mundo.

\section{Como o senhor enxerga o começo da popularização da sistemática filogenética no Brasil?}

Foi ótimo. Mudou radicalmente o que se fazia. Antigamente era só descrição de espécie, o que é fundamental, óbvio, mas hoje nós estamos na melhor situação da face da Terra. O Brasil é o segundo país que mais publica na Zootaxa, por exemplo. Se você comparar a situação acadêmica dos EUA com a nossa, nós somos o primeiro do mundo. ${ }^{15}$ Cresceu realmente, acho que a situação da zoologia está ótima. No entanto, poderia ter mais força política, mas em qualidade há grupos de pesquisa realmente esplêndidos: peixes, crustáceos, dípteros, são grupos de primeiríssima linha. Tanto que você vê que ninguém mais praticamente faz doutorado no exterior. Para quê? Vai aprender o quê? Hoje, com as facilidades do CNPq e da Fundação de Amparo à Pesquisa do Estado de São Paulo (Fapesp), já não há necessidade. Agora o pessoal viaja para ver os espécimes-tipo e manter contato. Mestrado no exterior nem pensar, doutorado é raríssimo, não há necessidade alguma. Em sistemática, nós somos muito melhores que a maioria dos países do mundo. Espero que continue assim.

Como o senhor viu o início da sistemática filogenética numérica (cladística numérica), o uso de computadores e a defesa de procedimentos analíticos?

O problema é que hoje isso virou dogma. Ninguém questiona o fundamento teórico, é receita de bolo. Coloca tudo no computador e sai o cladograma. Há erros de lógica, erros incríveis, mas ninguém questiona, isso que é o diabo! Falta preparação para o pessoal.

Talvez uma pessoa que entendesse bastante de teoria, utilizando a ferramenta da cladística numérica, pudesse ter resultados mais confiáveis...

\footnotetext{
${ }^{14}$ Jorge Llorente-Bousquets, professor do Departamento de Biologia Evolutiva da Universidad Nacional Autónoma de México.

${ }^{15}$ O Brasil é o país com a maior quantidade de autores (1.418) publicados na Zootaxa, uma das principais revistas de taxonomia do mundo, desde o seu início, em 2001.
} 
Não sei, isso é muito complicado. Algo que eu gostaria de fazer na linguística era escrever os termos em alfabeto fonético internacional e botar isso no computador para ver o que sai com os diferentes programas da cladística. Seria lindo. Digo isso porque, no indoeuropeu, já se sabe como foi a transformação, a 'evolução' das línguas. Linguística e filogenética são a mesma coisa. E alguns trabalhos com sistemática filogenética resultam em coisas absurdas, um trilhão de árvores, máximo consenso etc. O pessoal não sabe o que é parcimônia. Falta epistemologia, filosofia da ciência. Ninguém estuda base lógica: se o resultado parece errado, muda um parâmetro e faz outra árvore.

Por que o senhor nunca publicou um manual de análise filogenética?

Nunca pensei em publicar um manual de análise filogenética. Já existiam vários desses livros, como o do Edward Wiley (1981), o Phylogenetics: the theory and practice of phylogenetic systematics, que por sinal é cheio de erros, e também outros livros dos americanos.

\section{Quando o senhor se aposentou?}

Em 1997. Passei os últimos anos no Instituto de Estudos Avançados da USP, no grupo de lógica. Foram anos maravilhosos, o Newton da Costa $^{16}$ é o maior gênio do Brasil. Depois voltei para cá, mas não tinha mais tanta motivação para trabalhar no museu. Além disso, começaram uma discussão sobre mudanças na aposentadoria, se cortariam ou não os salários. Nesse momento, decidi me aposentar um ano antes do prazo final. Não fez muita diferença. Saía mais caro vir da minha casa para o museu todos os dias. Mas isso foi um erro: nunca trabalhei tanto na vida quanto depois de aposentado!

O senhor está trabalhando atualmente na produção de um dicionário dos nomes populares dos animais. Quando começou a preparar essa obra?

Comecei a trabalhar no dicionário justamente depois de me aposentar, quando tinha uma bolsa da Universidade Rural do Rio de Janeiro (UFRRJ). Sempre quis trabalhar nisso, sempre gostei, desde o tempo que lia o dicionário do von Ihering ${ }^{17}$, que é um monumento maravilhoso. Quando me aposentei, pensei: "ah, vou começar a fazer". Comecei fichando o dicionário Aurélio, e aí foi, foi, foi, e não tem fim. Vai ser uma obra póstuma. Não tenho perspectiva de término, não tem fim mesmo! Mas vou ter que acabar este ano. O problema é que todo dia se descobre coisa nova, às vezes até em trabalhos recentes. Tiro amostragem pelo Google, porque não dá para acompanhar tudo, são milhares de trabalhos por ano. O Google é uma ferramenta linda porque ele te dá até os nomes populares.

Tem muita gente que publica trabalhos de etnozoologia no Brasil. E essa é uma área que antes era tabu. Começou um grupo maravilhoso na Universidade Estadual de Feira de Santana. E no Nordeste, na Bahia, tem gente muito boa trabalhando nisso. É uma coisa

\footnotetext{
${ }^{16}$ Newton Carneiro Affonso da Costa foi professor titular da USP e da Universidade de Campinas e um dos criadores da lógica paraconsistente.

${ }^{17}$ Rodolpho Theodor Wilhelm Gaspar von Ihering (1883-1939), zoólogo brasileiro celebrizado pelo seu Dicionário dos animais do Brasil, de 1940. Filho de Hermann von Ihering (1850-1930), naturalista alemão, diretor do Museu Paulista entre 1894 e 1915.
} 
linda porque você resgata uma cultura de milênios, transmitida oralmente. E, no fundo, isso é um estudo nacional de línguas. Os nossos dicionários de línguas são paupérrimos.

\section{Há algum colaborador nesse dicionário?}

Sim, o Dante Martins Teixeira. ${ }^{18}$ Também consultamos os colegas, para os nomes científicos, mas para o levantamento em si somos apenas nós dois.

Parece um trabalho pesado, mas não é. É uma delícia quando encontramos um manuscrito inédito, coisa que nunca se viu. É motivador! Adoro isso. O trabalho final vai ficar com umas cinco mil páginas, quando inserirmos as figuras. Já está com três mil páginas de texto. O problema agora é 'limpar' tudo isso.

Poderíamos lançar volumes pequenos, mas é impossível por causa das repetições e dos sinônimos. Isso implicaria em ter que voltar na sinonímia do nome principal em cada volume. É de fato impossível porque está tudo ligado. É infernal. Se partíssemos em volumes menores, para procurar um nome, teria que se procurar em tudo. Não dá. É um monstro! Criei um monstrinho! E depois o problema é que ficam alterando os nomes científicos. Mudou cobra, pombas! Mudou cascavel. As jararacas mudaram de nome. Está um inferno. De sapo não sobrou nada porque os gêneros de sapo e perereca agora são outros, alteraram tudo. Os peixes são exceção. Tem catálogo mundial, está ótimo para trabalhar com eles, 'limpinho', só que também tem modificações de vez em quando. Agora entre os anfíbios e répteis foram mudanças grandes. O gênero Bufo, por exemplo, não existe mais.

Essas alterações ocorrem porque os pesquisadores fazem revisões e filogenias e mostram que o que se considerava um gênero não é de fato um gênero e coisas do tipo... As espécies de pererecas descritas para o gênero Hyla não existem mais. Foram divididas em um monte de outros gêneros. O gênero de serpentes Crotalus acabou, agora é Caudisona. Com isso, tem que se mudar tudo no dicionário. Outra complicação é quando entram espécies novas, espécies ainda não descritas, mas que têm nomes extremamente comuns. Aí você tem que mudar toda a numeração do dicionário e os sinônimos, espalhados por todo canto. Isso é muito trabalhoso. Quando é nome novo é só incluí-lo. Quando é espécie nova, e sempre estão entrando espécies, fica mais complicado. Isso vale, por exemplo, para os peixes. Eles correspondem a $60 \%$ do dicionário. Muito desse conhecimento vem do povo, dos índios... Que eu saiba, só os loucos aqui estão fazendo um dicionário assim...

\section{Como o senhor foi para a Universidade Federal do Rio de Janeiro (UFRJ)?}

Fui para a UFRJ por causa do meu aluno José Roberto Pujol Luz ${ }^{19}$, que me convidou. Ficamos trabalhando juntos um ano e meio, ministrando aulas na pós-graduação, por causa da bolsa do CNPq. Dava aula de sistemática, biogeografia e história da biologia... Aquelas coisas de sempre.

O que o fez voltar a trabalhar com Diptera (no projeto temático da Fapesp) e publicar com o grupo?

${ }^{18}$ Dante Martins Teixeira, professor do Museu Nacional da Universidade Federal do Rio de Janeiro.

19 José Roberto Pujol Luz é atualmente professor do Departamento de Zoologia da Universidade de Brasília. 
O Dalton de Souza Amorim ${ }^{20}$ começou o projeto e me convidou para participar. E a bolsa era boa. Eu tinha que sustentar minha filha na Austrália!

É possível fazer uma comparação do ambiente acadêmico na área de zoologia quando começou em relação ao ambiente contemporâneo?

Hoje o nível está muito superior. Tem um pessoal realmente profissional. Antigamente eram discussões superficiais, de pequenos detalhes de nomenclatura e outras bobagens. Hoje o nível é outro. O pessoal está interessado em sistemática filogenética, biogeografia... Antigamente havia grupinhos separados e poucas relações entre pesquisadores. Um dos nossos problemas no PNZ foi justamente o de levantar as instituições que faziam zoologia porque só conhecíamos as principais. Isso mudou muito. No entanto, como a zoologia brasileira ficou muito grande, acaba faltando uma liderança na área. Seria necessário um líder teórico, que revolucionasse as coisas, que é o mais difícil. E a conjuntura não está para isso.

Qual o seu legado para a sistemática filogenética feita no Brasil e fora daqui?

Minha principal contribuição foi a formação de pessoal. Bem ou mal isso serviu de incentivo para carreira, não só aqui, mas em outros países. E a coleção de Diptera do MZUSP, que é uma belezinha.

O período do PNZ foi realmente lindo, a criação da SBZ também. Há alguns trabalhos em específico de que gosto: o da história da dipterologia, que é o mais citado (Papavero, 1971, 1973); também gosto daquele com os dípteros Oestridae (Papavero, 1976). O que mais? Ah, claro, os trabalhos sobre folclore...

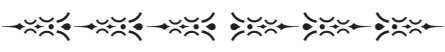

${ }^{20}$ Dalton de Souza Amorim, professor de Zoologia da USP, campus Ribeirão Preto e ex-orientando de pós-graduação de Papavero. 


\section{REFERÊNCIAS}

CARRERA, Messias; PAPAVERO, Nelson. Saropogonini neotropicais (Diptera, Asilidae, Dasypogoninae). Studia Entomologica, Petrópolis, v.5, p. 39-64. 1962.

HENNIG, Willi.

Insect phylogeny. New York: John Wiley \& Sons. 1981.

HENNIG, Willi.

Phylogenetic systematics. Urbana: University of Illinois Press. 1966.

HENNIG, Willi.

Phylogenetic systematics. Annual Review of Entomology, Palo Alto, v.10, p.97-116. 1965.

HENNIG, Willi.

Flügelgeäder und System der Dipteren unter Berücksichtigung der aus dem Mesozoikum beschriebenen Fossilien. Beiträge zur Entomologie, Keltern, v.4, n.3-4, p.245-388. 1954.

MACHADO-ALLISON, Carlos Eduardo; PAPAVERO, Nelson.

Um novo gênero e uma nova espécie de Corrodentia do Brasil: Lenkoella neotropica (Reuterellinae, Elipsocidae). Papéis Avulsos de Zoologia, São Paulo, v.15, n.24, p.311-315. 1962.

PAPAVERO, Nelson.

The world Oestridae, mammals and continental drift. Haia: Dr. W. Junk b. v. Publishers. 1976.

PAPAVERO, Nelson.

Essays on the history of neotropical dipterology, with special reference to collectors (1750-1905), v.2. São Paulo: Museu de Zoologia, Universidade de São Paulo. 1973.

PAPAVERO, Nelson.

Essays on the history of neotropical dipterology, with special reference to collectors (1750-1905), v.1. São Paulo: Museu de Zoologia, Universidade de São Paulo. 1971.
PAPAVERO, Nelson.

Quatro novas espécies de Microdontinae do Brasil (Diptera, Syrphidae). Papéis Avulsos de Zoologia, São Paulo, v.15, n.25, p.317-326. 1962.

PAPAVERO, Nelson; BALSA, Josette. Introdução histórica à biologia comparada, com especial referência à biogeografia. (v.1. Do gênesis à queda do Império Romano do Ocidente). Belo Horizonte: Biótica \& Sociedade Brasileira de Zoologia. 1986.

PAPAVERO, Nelson; TEIXEIRA, Dante Martins. Os viajantes e a biogeografia. História, Ciências, Saúde - Manguinhos, Rio de Janeiro, v.8, supl., p.1015-1037. 2001.

PAPAVERO, Nelson; TEIXEIRA, Dante Martins; LLORENTE-BOUSQUETS, Jorge. História da biogeografia no período pré-evolutivo. São Paulo: Plêiade. 1997.

PRADO, Ângelo Pires do.

Syringogastridae: uma nova família de dípteros Acalyptratae, com a descrição de seis espécies novas do gênero Syringogaster Cresson. Studia Entomologica, Petrópolis, v.12, n.1-4, p.1-32. 1969.

SANTOS, Charles Morphy Dias.

Os dinossauros de Hennig: sobre a importância do monofiletismo para a sistemática biológica. Scientiae Studia, São Paulo, v.6, n.2, p.179-200. 2008.

WILEY, Edward.

Phylogenetics: the theory and practice of phylogenetic systematics. New York: WileyInterscience. 1981.

ZARUR, George de Cerqueira Leite. $A$ arena científica. Campinas: Autores Associados. 1994. 